\title{
Research Paper: Factor Analysis of the Impact of Industrial Areas on Rural Development: A Case Study crossuark of Farahan Industrial Area in Iran
}

\author{
Soudeh Golabi ${ }^{1}$, Mohammad Sadegh Ebrahimi ${ }^{*}$ \\ 1. Graduated student, Department of rural development, College of Agriculture, Isfahan University of Technology, Isfahan, Iran. \\ 2. Assistant professor, Department of rural development, College of Agriculture, Isfahan University of Technology, Isfahan, Iran.
}

Article info:

Received: 19 Dec. 2017

Accepted: 15 July 2018

Keywords:

Rural industrialization, Rural development, Farahan, Factor analysis
Citration: Golabi, S., \& Ebrahimi, M. S. (2018). Factor Analysis of the Impact of Industrial Areas on Rural Development: A Case Study of Farahan Industrial Area in Iran. Journal of Sustainable Rural Development, 2(1-2), 51-60. https://doi. org/10.32598/jsrd.01.03.250

https://doi.org/10.32598/jsrd.01.03.250 
fluenced by a wide range of factors, such as equality of life, employment, and income. To identify the impact of individual factors, to interpret the relationships among them, to gain insight into the underlying structure of the variables involved, to assess the control on those variables for rural development, and to evaluate the impact of the variables on the spatial distribution of nonfarm jobs, factor analysis is an appropriate technique to apply (Matalas and Reiher, 1967). The rural non-farm sector encompasses all non-agricultural activities including mining and quarrying, household and non-household industries, processing, repair, construction, communications, storage, trade and commerce, transportation, and other services in villages. Yet, industry is usually the most dominant non-farm job. Therefore, the approach to rural non-farm development has becomes synonymous with rural industrial development. Indeed, rural industry occupies a central place in rural development, employment and welfare policies (Chadha, 1996). Through factor analysis, it is possible to identify several rural development factors reasonably, but that is a very subjective task to interpret those factors in terms of actual controlling sources and processes. Regardless of its subjectivity, factor analysis has provided vital information about the relationships of basic variables involved in rural development. So far, this technique has been applied to several sub-disciplines of sociology such as rural development studies, rural management, and rural planning.

\section{Literature Review}

According to the World Bank report (1975), rural development generally refers to the process of improving the quality of life and economic well-being of people living in relatively isolated and sparsely populated areas. In fact, itt involves strategic planning to improve the economic and social life of rural poor groups and to extend the benefits of development to those who seek a living in rural areas. The poor groups in focus are small-scale farmers, tenants and the landless (Dixon, 1997). Aslam (1981) defined this concept of rural development as a dynamic process leading to higher levels of living and a better quality of life. Similarly, Schumacher (1983) considered rural development as the process of promoting people's skills and knowledge through instruction so that they can rely on and help themselves. The available definitions and interpretations highlight the central point that rural development is about improving the welfare and productivity of rural communities, about the scope and process of improving the participation of rural people in their own affairs, and about the ways and means of making this possible (Ocheni and Nwankwo, 2012).
Rural industrialization, as a concept relevant to rural development, has been defined as a means of reducing unemployment and poverty in rural areas as well as decreasing rural-urban migration (Chadha, 1996). Through rural industrialization, technical changes occur to improve the quality of life for the rural population. Improvement of the income and the standards of living of factory employees is the most direct impact of rural industrialization (Bertrand and Osborne, 1959). The rural non-farm sector can contribute to economic growth, rural jobs, poverty reduction, and spatially balanced population distribution. (Lanjouw et al., 2000). Foss (1997) emphasized the importance of small-scale industries in rural areas and creation of more jobs in those areas than in urban areas. To Saith (1992), a fairly equitable income distribution can be stimulated by rural industry. In a paper titled "industrialization and rural development in Nigeria: towards overcoming the pitfalls of the past", Gofwen (2001) exanimated the relationship between rural development and industrialization in Nigera. He suggested policies to establish an industry based on the available raw materials within each region. If pursued, the policies would not only facilitate the development of the rural areas and improve employment opportunities there but also serve to divert the over-dependence of the nation on one item as the only foreign exchange earner.

Non-farm sector income distribution in support of the poor is also of significance. The statistical results of a study conducted in six Texas communities showed that rural industrialization had a statistically significant positive effect on the income of those employed (Reinschmiedt and Jones, 1977). Agricultural development linked to rural industrial growth contributes to the improvement of peasants' income (Xu and Tan, 2002). As Sigurdson (1975) showed, rural industry had played an important role in the social transformation of the Chinese countryside and contributed considerably to the rectification of the imbalance between urban and rural areas. Rural industrialization may have a few impacts on job patterns as well (Sigurdson, 1975). Parikh and Thorbecke (1996) examined the impact of rural industrialization on village life and economy. The result showed that the decentralization of industries had contributed considerably to rural development and poverty alleviation in rural areas nearby factories. It was found that the people had become more aware of the advantages of education, investment in agriculture had risen, exploitation of laborers had significantly reduced, and the factory salaries had reduced poverty and lowered income inequality among household classes. In a theoretical approach, Barrel (1984) referred to conflicting views about employment and income levels as targets of rural industrialization 
and stated that these targets treat separately under static conditions. For example, in a long-term survey, the experimental data related to rural industries in northeastern Brazil showed that import substitution policies to reach development goals can be effective. (This conclusion referred to some indications of the best industrialization policies for the achievement of alternative development objectives) (ibid). It has also been identified that lack of facilities such as electricity, gas and water, frequent changes in the prices of raw materials, shortage of raw materials, political unrest, high interest rates on borrowings, high transportation cost, lack of financing for ongoing concerns, and inadequate infrastructure are the major constraints in the development of the manufacturing sectors of SMEs in Bangladesh (Ahmed et al., 2011). Chang-hong (2000) examined the impact of rural industrialization on the rural-urban transition in China by analyzing the regional uneven development among provinces. It was concluded that the fast industrialization of rural areas had brought many radical transformations in the rural space of China, especially in the formation of new rural economic, social and geographical spaces and the uneven development of rural-urban transition.

Rural development, in general, entails the actions and initiatives taken to improve the standard of living in non-urban neighborhoods, countrysides, and remote villages. These communities are marked with a low ratio of inhabitants to open space. Agricultural activities may be prominent in this case, whereas economic activities would relate to the primary sector, i.e. production of foodstuffs and raw materials. Industrial towns are the areas that have been established to cherish industry, research, and technology. They support services such as engineering designs, training, informing, consulting, commercial intellectual rights, and infrastructural facilities. In the early 1990s, rural development was somehow defined for the agricultural sector. But, nowadays, in addition to agricultural development, other domains such as industry, employment, sub-categories of the rural economy, education, health care and infrastructure can be concerned with rural development (Hart, 1999). Some studies in the literature have emphasized positive links between agricultural development and the growth of non-farm activities. Recently, it has been argued that an emphasis on agricultural development is unnecessary in a globalized world with increasing mobile capital, and that policies which encourage investment in the rural non-farm sector may be the best means of reducing rural poverty (Foster, 2003; Haggblade, Hazell, and Reardon, 2001). In Iran, it was first conceptualized that to establish services and infrastructures would be possible. The intended services were of both network and infrastructural types, like water supply, sanitation, electricity, roads, drainage, schools, health centers, market places and other facilities in rural areas to increase rural prosperity and prevent uncontrolled rural migration to cities. But, nowadays, it has been proved that to create employment and income is a major factor to pursue for rural development.

In many countries such as Iran, agricultural units cannot response to rural needs; thus, attention should be paid to non-farming tasks. Following the rural industrialization approach, this paper discusses the impact of rural industrialization on rural development specifically on the generation of new jobs, employment patterns for men and women, equitable distribution of income, standards of living, reduction of rural-urban migration, promotion of life welfare criteria such as health, education, communication and telecommunication index, consumption patterns (i.e. of food, clothing, and consumer goods), housing and expenditures, insurance, job security and fulfillment, education, literacy, participation, and increase of motivation and tendency to stay in village.

The theoretical and practical implications of rural industrialization and its role in rural development can be summarizes as in the following.

First, the employment problem is decreased for rural people. Rural industries or expansion of non-farm jobs is a logical way out of the rural employment problem. Creation of income for rural people and increase of their tendency to stay in villages is a planned strategy that may prevent many rural people from migrating to urban and commercial centers. Rural industries can utilize local talents and 'slack' resources which cannot otherwise be used in urban, modern industries. The social cost of such raw materials is very low, but the benefits could be quite high. A typical example is the various types of waste-recycling activities (Geodry, 1977; Saith, 1992; Chadha, 1996; Parikh and Thorbecke, 1996; Pinard, 1988; Foss, 1997).

Second, the increase of tendency to stay in villages and the reduction of migration is the reason for the increase of young people or active population and improved facilities in rural areas. Government planning in these areas predisposes the improvement of standards of living and the expansion of services such as shopping centers, banks, education, health and safety (Chadha, 1996; Sigurdson, 1975; Bertrand and Osborne, 1959).

Third, remaining of young people in rural areas, improved rural structures, reconstruction of houses, using 
durable materials in house construction, improvement of transportation and roads are some other outcomes of rural industrialization.

Fourth, rural industrialization has significant spin-offs for agricultural development as well. The extension and deepening of the skill profile of the rural workforce, a sharing of rural infrastructures as well as local availability of certain inputs, construction materials and car repair services are examples of what rural industries can do to boost agricultural growth and productivity (Bertrand and Osborne, 1959; Sigurdson, 1975; Geodry, 1977; Parikh and Thorbecke, 1996; Foss, 1997).

Fifth, the remaining of the population in rural areas leads to the creation of markets in these areas, which, in turn, leads to an increase in investments there (Sigurdson, 1975; Chadha, 1996; Bertrand and Osborne, 1959).

Many studies have reported the effects of non-farm employment on rural development, but are certain social impacts that have remained ignored by those studies; hence, more study is needed. This paper reports the results of a survey that identified the impacts of creating industrial towns on nonfarm employment in villages, and those impacts are prioritized too. The study seeks to use factor analysis to identify the useful rural development indicators in a rural industrial area of Iran. The factor model is expected to describe the main indicators and processes involved in the development of Farahan rural area.

\section{The case study area and the data source}

The study was carried out as a piece of field research, and a questionnaire was designed as a tool with which to derive data for the rural people who lived in the study area. The validity of the research was assessed by experts' opinions, and the reliability of the questionnaire was confirmed using a pilot test. A Cronbach Alpha coefficient of higher than 0.7 would mean that the research tool was reliable. The population of the research included 236 industrial employees selected in the study area, Farahan.

Industrial area is located in the center of Markazi Province, central west of Iran (Figure1).

\section{Methodology and the analytical frame- work}

This study is a piece of applied research carried out by using a survey method. Applying a multistage sampling technique, 236 people were selected randomly. The data were collected from structured interviews and field observation. To examine the reliability of the questionnaire, a pilot test was conducted with 236 participants. Cronbach Alpha coefficients were calculated along with Likert scales. The reliability of the questionnaire was determined by a Chronbach alpha test. The alpha value was considered in the range 0 to 1 , and the internal reliability of the items was found through this coefficient. If the coefficient was zero, it would show the full unreliability of the items, but a coefficient of one would show full reliability. If the alpha value was more than 0.7 , the questions and the items would be considered valid for testing the concept and the related variables. According to Table 1 , the questions and the items of the questionnaire all had a higher value than 0.7 .

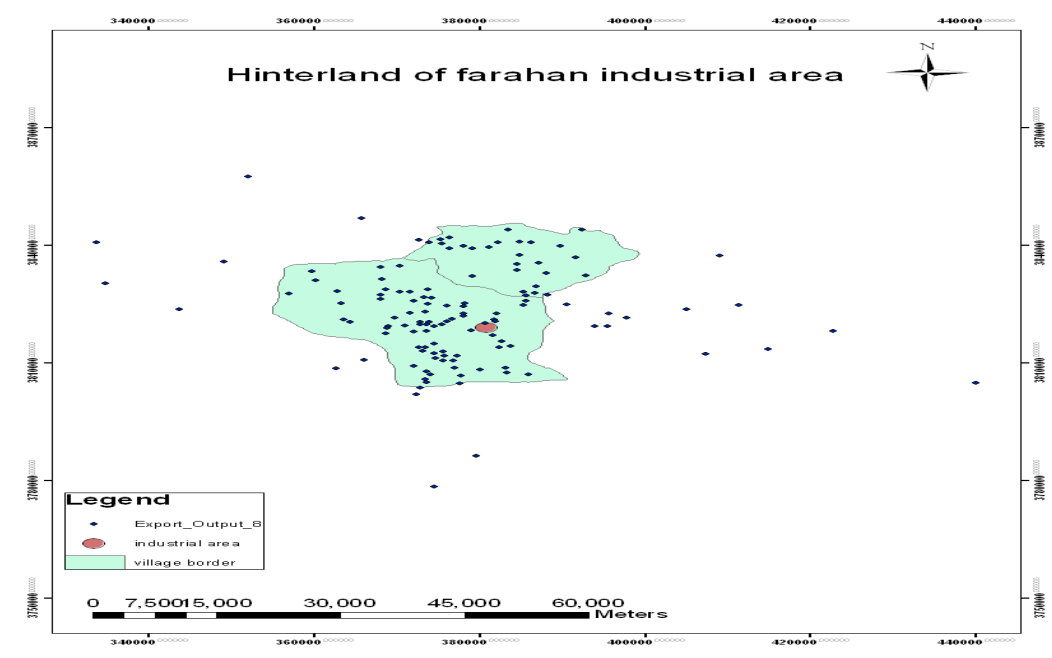

Figure 1. Farahan industrial area in Markazi province, Iran 
Table 1. Reliability analysis

\begin{tabular}{ccc} 
Scale & No. of items in the scale & Alpha value \\
\hline Economic factor & 10 & 0.888 \\
Social factor & 18 & 0.873 \\
Infrastructure factor & 4 & 0.930 \\
\hline & & JSR
\end{tabular}

To determine the appropriateness of the data and to measure the homogeneity of the variables that attracted farmers to group activities, Kaiser-Meyer-Olkin (KMO) and Bartlett's test measures were applied. These statistical tools show the extent to which the indicators of a construct belong to each other. In this study, KMO and Bartlett's test results proved that the data were proper enough for factor analysis. The results are presented in Table 2.

As it can be seen, $\mathrm{KMO}$ was 0.848 , which is larger than 0.5 . Thus, the number of participants was suitable for factor analysis. In general, the closer to 1 the KMO value is, the higher the sample validity will be. According to the above table, the sphericity of Bartlett's test was found to be 1035.93 with the significance of $p=0.000$. Because this value is significant, it is concluded that the factors were not classified well enough, and the questions about each factor had congeneric correlations with one another. Factor analysis was applied as the main statistical technique to analyze the data. The main object of this technique is to classify many variables into a few factors based on the relationships among the variables. For this purpose, 14 variables were selected for the analysis.

Factor analysis is a statistical method that is based on the correlations among multi-variables. The purpose is to cut most variables to a lesser underlying factors measured by those variables. The factors are formed by grouping the variables that have a correlation with each other. There are mainly four stages in factor analysis (Emin et al., 2007). a. Derivation of a matrix for the variables: Variables are selected, and an intercorrelation matrix is generated to include them all. The matrix is a $\mathrm{k}$ ( $\mathrm{k}$ equals variables) array of the correlation coefficients. When the correlation between two variables is low, it is not feasible for these variables to have a common factor, and, therefore, this correlation is not studied. Kaiser-Meyer-Olkin (KMO) and Bartlett's tests of sphericity (BTS) are then applied to check if the remaining variables are factorable. The KMO value should be greater than 0.5 for a satisfactory factor analysis. BTS, on the other hand, should show that the correlation matrix is not an identity matrix by giving a significance value smaller than 0.001 .

b. Extraction of the factors: Factors are extracted from the correlation matrix described in the first stage. Each variable is standardized to have a mean of 0.0 and a standard deviation of 71.0. So, the eigenvalue of a factor should be greater than or equal to 1.0 if it is to be extracted.

c. Rotation of the factors: Sometimes one or more variables may load about the same on more than one factor, making it complicated to interpret the factor(s). So, the factors involved are rotated to clarify the relationship between them and the variables. While various methods can be used for factor rotation, the Varimax method is the most commonly used one.

d. Naming of the factors: The results are derived by analyzing the factor load of each variable. A proper name is given to each factor by considering the factor load (Emin et al., 2007).

Table 2. KMO measure and Bartlett's test to assess the appropriateness of the data for factor analysis

\begin{tabular}{lcc}
\hline KMO & \multicolumn{2}{c}{ Bartlett's test of sphericity } \\
\hline & Approx. chi- square & Sig \\
0.848 & 2165.161 & 0.000 \\
\hline & & C JSRD
\end{tabular}




\section{Results}

The Kaiser criterion (1960) was used to select the underlying factors or the principal components explaining the data. In this study, the number was decided by leaving out the components with corresponding eigenvalues of less than one. This is a rule of thumb when conducting Principal Component Analysis (PCA) using a correlation matrix. Because PCA uses the earlier communalities of one, it tends to inflate factor loadings, which makes the identification of patterns relatively easy. In factor analysis, the sum of the squares of factor loadings (eigenvalue) shows the relative importance of each factor to explain the total variance. Three factors were suggested by the criterion of eigenvalues. According to Table 3 , the eigenvalues for factors 1 through 3 are 4.070, 3.237 and 1.296 respectively. The true factors that were retained explained $61.45 \%$ of the total variance. The percentage of trace (i.e. the variance explained by each of the three factors) is also shown in Table 3.

The varimax rotated factor analysis is shown in Tables 4, 5 and 6. To determine the factors, loadings greater than 0.50 were considered significant. The first factor, i.e., the economic factor, explained $29 \%$ of the total variance, and five variables were loaded significantly. These variables are presented in Table 4 . The eigenvalue of the economic factor is 4.07 , which is placed at the first priority in rural industrialization.
The results of this research showed that three factors explain $61.450 \%$ of the total variance of the components that impact rural industrialization in Farahan. These factors include the economic, social and infrastructure ones. The economic factor with the effect of $29 \%$ has the most important impact on rural industrialization in the villages of Farhan County. In this factor, five variables are loaded significantly. These variables include insurance expansion, raise in agricultural income, raise in non-agricultural income, job opportunities, and temporary job.

The second factor is associated mostly with social variables. So, it can be called "social factor". The eigenvalue for this factor is 3.237 , which explained $23.1 \%$ of the total variance (Table 5). The social factor with an effect of $23 \%$ has an important impact on rural industrialization in the villages of Farhan County. In this factor, four variables are loaded significantly. They include development of services, raising interest in rural life, raising interest to stay in Farmahin County, and development of learning skills.

The name assigned to the third factor is "infrastructure effects". This factor with an eigenvalue of 1.296 explains $9.3 \%$ of the total variance (Table 6 ). The infrastructure factor with an effect of $9.3 \%$ has an important impact on rural industrialization in the villages of Farhan County. In this factor, three variables are loaded significantly, including renovated homes, improved roads, and resistant materials in the houses made.

Table 3. The extracted factors, eigenvalues and variance explained by each factor

\begin{tabular}{cccc}
\hline Factor & Eigenvalue & \% of variance & Cumulative \% of variance1 \\
\hline 1 & 4.070 & 29.069 & 29.069 \\
2 & 3.237 & 23.122 & 52.191 \\
3 & 1.296 & 9.258 & 61.450 \\
\hline
\end{tabular}

Table 4. Variables loaded in the first factor using varimax rotated factor analysis

\begin{tabular}{ccc}
\hline Name of factor & Variables loaded in the factor & Factor loadings \\
\hline & Insurance expansion & 0.950 \\
Economic factor & Raise in agricultural income & 0.916 \\
& Raise in non-agricultural income & 0.957 \\
\hline
\end{tabular}


Table 5. Variables loaded in the second factor using varimax rotated factor analysis

\begin{tabular}{lcc}
\hline Name of factor & Variables loaded in the factor & Factor loadings \\
\hline Social factor & Development Services & 0.674 \\
& Raising interest in rural life & 0.560 \\
Raising interest to stay in the Farmahin county & 0.692 \\
\hline
\end{tabular}

Table 6. Variables loaded in the third factor using varimax rotated factor analysis

\begin{tabular}{ccc}
\hline Name of factor & Variables loaded in the factor & Factor loadings \\
\hline \multirow{2}{*}{ Infrastructure factor } & Renovated homes & 0.716 \\
& Improved roads & 0.582 \\
& Resistant materials in house construction & 0.684 \\
\hline
\end{tabular}

\section{Discussion}

The debate on which strategies for rural development are most "pro poor" continues to some extent. Despite the fact that a large part of the world's poor population resides in rural areas, empirical evidence on the relative efficacy of farm and non-farm growth, as a means of reducing rural poverty and inequality, has been limited and inconclusive. One key limitation has been the absence of appropriate data. A dataset for examining this efficacy must be of sufficiently long duration to capture significant sectoral transformation, of sufficient spatial variation to contain different patterns of growth, and sufficiently disaggregated to permit the examination of income by sector at the household level. In rural development, industrialization has played an effective role. So, owing to its great effects on the social and economic development of the country, industrialization is regarded as one of the solutions to rural problems. These problems include income difference between rural and urban families, rise of unemployment in labor force, and migration because of unemployment. One of the most important problems in many developing countries is unemployment. Expansion of industrial plants in rural regions can raise jobs and income in those places. Raising income and jobs is known as an important issue in rural industrial towns. The findings of this study show that jobs in rural areas raise the non-agricultural income. The farmers buy the land from others and acquire more land to raise their income in the agricultural sector. Associated with it are ancillary jobs, done for example by temporary workers from the rural labor force, and expansion of social insurance and income stability. Industrializa- tion is an approach with which to reach sustainable development and accelerate social and economic growth. Nowadays, in many developing countries, rural development depends on the industrialization of rural areas. Otherwise, agricultural units cannot response to rural needs. This is what brings the rural industrialization approach into focus. Rural industrialization or setting up industries in rural areas, as an important and most common procedure for non-agricultural economic development, serves as a process that affects the economic and social characteristics of rural areas. Lack of some main agricultural production parameters like water resource and rich soil in these areas, despite adequate manpower, leads to an increasing rate of migration from rural areas and involvement of the destination areas with the side effects of this immigration. Establishment of industries in rural areas that have low agricultural potentials may serve as an effective tool to avoid immigration, maintain the rural people in their own home villages, and improve diverse social and economic lifestyle indices such as job, income, health, education and access to sanitary facilities. Since long, establishing industries in rural areas has been considered by regional planers as a means of achieving rural sustainable development and reginal balance through promotion of human resources and economic indicators.

With respect to rural development, industrial zones should be the focal point of economic development policies. These zones are intended to create jobs for the local people. The expansion of industrial plants in rural regions creates a combination of activities in both agriculture and industry to raise jobs and income in those 
regions. The results of this research showed that the influential factors can be categorized into three types: economic, social and infrastructural. The results also point to a positive correlation between rural industrialization and life welfare improvement. The industrialization process in the rural areas of the research zone proved to involve all the three afore-mentioned factors. As far as the economic factor is involved, agricultural and nonagricultural income has risen, and new jobs opportunities have been created. From the viewpoint of the social factor, the residents have become interested in rural life and their skills are enhanced. As for the infrastructures, industrialization has improved such infrastructures as rural roads and rural homes.

The positive impact of economic development on local society largely depends on the capacity of a newly established industry to absorb local labor and to stimulate other local businesses. If the new industry forms an isolated enclave with its labor force and operates with supplies that are almost entirely imported, it is likely to create resentment and frustration. It is also possible that economic gains will be made at the expense of other factors that affect people's quality of life, such as degradation of the environment.

\section{Conclusion}

To alleviate the employment problem in rural areas, setting up industries or expanding non-farm jobs can be a logical way out of the problem. Also, to raise rural people's income and increase their tendency to stay in villages, a planned strategy is required for rural industrialization. Any plan in this regard should prevent migrating to urban and commercial centers and utilize local talents and 'slack' resources which cannot otherwise be used. The social cost of such plans is very low, but the benefits could be quite high. A typical example is the establishment of various types of waste-recycling activities.

Once the tendency to stay in villages is increased and migration is reduced, the number of young people and the quantity of active population start growing in rural areas and facilities begin to improve. In this case, government planning plays a key role; standards of living should be promoted by expanding services and accommodations such as shopping centers, banks, education, health, and safety. In addition, the physical or structural features of villages should be qualified by reconstruction of houses and using durable materials in house construction. Remaining of the population in rural areas entails creation of markets an increase of investments in those areas.
The industrialization of villages has significant outcomes for agriculture as well. The extension and deepening of the skill profile of the rural workforce, sharing of rural infrastructures, and local availability of certain facilities such as machine repair services are examples of what boosts agricultural growth and productivity.

\section{Acknowledgment}

This study was based on a research project financially supported by Isfahan University of Technology, Iran, which is highly appreciated.

\section{Conflict of Interest}

The authors declared no conflict of interests.

\section{References}

Ahmed, F, Rahman, M., Mizanur and Haque, M., (2011). Constraints of Manufacture based Small and Medium Enterprise (SME) Development in Bangladesh, Journal of Social and Development Sciences, 1: 91-100.

Aslam, M. (1981). Rural Development in India. Journal of Bangladesh Academy for Rural Development, Comilla, X(1/2).

Barrel, R., (1984), Rural industrialization objectives: the incomeemployment conflict, World Development, vol. 12, pp129140.

Bertrand, A.L. and Osborne, H.W, (1959). The impact of industrialization on a rural community, Journal of Farm Economics, 41: 1127-1134.

Chadha, G.K, (1996). The industrialization strategy and growth of rural industry in India, International labour Organization, New Delhi

Chang-hong, M., (2000). New rural spaces: the impact of rural Industrialization on rural-urban transition in china, Chinese geographical science, 10: 131 - 137.

Dixon, Ch. (1997). Rural Development in Third World. Abuja: Family Economic Advancement Programme.

Emin, M. O., Emel, L. O., Ercan, E., \& Gamze, V. (2007). Industry financial ratios-application of factor analysis in Turkish construction industry. Building and Environment, 42, 385-392.

Foss, O. (1997). Establishment structure, job flows and rural employment. rural employment in OECD countries,39:3-15.

Foster, A.D., (2003), AEconomic Growth and the Rise of Forests.@ Quarterly, Journal of Economics, 118(2): 601-637

Geodry, l.y., (1977). Employment impact of rural industrialization lasalle parish Louisiana, Rural Economist, 39:3-15. 
Gofwen, R.L. (2001). Industrialization and rural development in Nigeria: Towards Overcoming the pitfalls of the past, Nigerian journal of social work, 5:74-90

Haggblade, S., PBR Hazell, and T. Reardon, (2001), "Strategies for stimulating equitable growth of the rural nonfarm economy in developing countries", Invited paper for keynote address at the 74th EAAE Seminar, Livelihoods and rural poverty: technology, policy and institutions, September 12-15,2001, Imperial College at Wye, United Kingdom

Hart, M, (1999), Guide to sustainable community indicators, North Andaver, Hart Environmental Data.

Himanshu, H., Lanjouw, P., Mukhopadhyay, A., \& Murgai, R. (2011). Non-farm diversification and rural poverty decline: A perspective from Indian sample survey and village study data.

Kaiser, H. F. (1960). The Application of Electronic Computers to Factor Analysis. Educational and Psychological Measurement, 20(1), 141-151. https:/ / doi.org/10.1177/001316446002000116

Lanjouw, J.O. and Lanjouw, P. (2001). “The rural non-farm sector: issues and evidence from developing countries", Agricultural Economics 261(1):1-23.

Matalas CN, Reiher JB.Some comments on the use of factor analysis.W ater Resour Res 1967;3(1):213 -223.

Ocheni, S and Nwankwo, B.C, (2012). Analysis and Critical Review of Rural Development Efforts in Nigeri

Osunade, M. A. (1978). A descriptive profile of the non-farm sector: A case study of Ipetu Ijesa, Oyo State, Nigeria. Africa Insight,8(1), 44-52.

Parikh, A and Thorbecke, E., (1996). Impact of rural industrialization on village life and economy: a social accounting matrix Approach", Economic Development and Cultural Change, 44: 351-377.

Pinard, J, (1988). The impact of industrialization on the development of the rural environment of the Poitou-Charentes district in the 19th and 20th centuries, Geografiska Annaler. Series B, Human Geography, 70:219-225.

Reinschmiedt, L and Jones, L, (1977). Impact of industrialization on employee income distribution in rural Texas communities, Agricultural Economics, 9: 67-72.

Saith, A., (1992). The rural non-farm economy: processes and policies, International Labour Organization, I.L.O.

Schumacher, E. F. (1983). Small is beautiful: a study of economics as if people mattered. University of Michigan: Abacus.

Sigurdson, J, (1975). industrialization in China: Approaches and results, World Development, 3:527-538

World Bank. (1975). Rural development (English). Sector policy paper. Washington, DC : The World Bank. http://documents.worldbank.org/curated/en/522641468766236

Xu, W. and Tan, K.C. (2002). Impact of reform and economic restructuring on rural systems in China: a case study of Yuhang, Zhejiang, Journal of Rural Studies, 18: 65-81. 
